\title{
PENGOLAHAN AIR PAYAU DENGAN FILTER ZEOLIT DAN BENTONIT
}

\author{
Nur Afifah ${ }^{1)}$, Ekha Yogafanny ${ }^{2}$, Andi Sungkowo ${ }^{3)}$ \\ 1)2)3) Jurusan Teknik Lingkungan, Fakultas Teknologi Mineral, \\ Universitas Pembangunan Nasional "Veteran” Yogyakarta \\ Email: afi.afifah.nur@gmail.com
}

\begin{abstract}
Abstrak
Desa Sukoreno, Kecamatan Sentolo, Kabupaten Kulon Progo memiliki kondisi air tanah dengan nilai TDS 1520 mg/L yang tergolong dalam air payau, sehingga penduduk tidak dapat mengonsumsinya. Air tanah dengan sifat payau dapat ditemukan pada beberapa sumur - sumur gali maupun sumur bor warga. Penelitian ini bertujuan untuk mengetahui teknik pengolahan air payau. Metode pengolahan air tanah payau menggunakan metode adsorpsi dengan membandingkan material zeolit dan bentonit dengan Hydraulic Loading Rate (HLR) 0,25 m/jam. Filter zeolit yang digunakan sebagai adsorben memiliki efektivitas penurunan konsentrasi TDS mencapai 41,78\%, salinitas $40 \%$, natrium $72,51 \%$, sulfat 43,36\%, $\mathrm{HCO}_{3} 53,14 \%$, kalium $88,89 \%$ dan kesadahan 36,88\%. Filter bentonit sebagai adsorben memiliki efektivitas penurunan konsentrasi TDS mencapai 49,4\%, salinitas 46,67\%, natrium $75,10 \%$, sulfat 45,80\%, $\mathrm{HCO}_{3} 37,96 \%$, kalium $-11,11 \%$ dan kesadahan $41,87 \%$. Sehingga filter zeolit lebih optimal dibandingan filter bentonit.
\end{abstract}

Kata kunci: adsorpsi, air tanah payau, bentonit, zeolit

\begin{abstract}
Sukoreno Village, Sentolo Sub District, Kulon Progo Regency has brackish groundwater, so the villagers can't consume it. The brackish groundwater can be found at some well. The aims of this research are to find out the water treatment, and the management of brackish water so it can be a source of clean water. The methods used are using zeolit and bentonite filter with Hydraulic Loading Rate (HLR) 0,25 m/hours. Zeolit filter as adsorben has efectivity to decrease TDS concentration up to $41,78 \%$, salinity $40 \%$, sodium $72,51 \%$, sulphate $43,36 \%$, $\mathrm{HCO}_{3}$ $53,14 \%$, potassium $88,89 \%$ and hardnesse $36,88 \%$. Bentonite filter as adsorben has efectivity to decrease TDS concentration up to 49,4\%, salinity 46,67\%, sodium 75,10\%, sulphate 45,80\%, $\mathrm{HCO}_{3} 37,96 \%$, potassium - $11,11 \%$ and hardnesse $41,87 \%$, so zeolite filter is more optimal than bentonite filter.
\end{abstract}

Keywords: adsorption, bentonite, brackish groundwater, zeolite

\section{PENDAHULUAN}

Air tanah merupakan air yang berada di bawah permukaan bumi, menempati ruang -ruang antar butir dan atau celah - celah tanah / batuan (Bahagiarti dkk., 2008). Air tanah banyak dibutuhkan masyarakat untuk memenuhi kebutuhan sehari - hari. Air tanah tersebut harus memenuhi kriteria berdasarkan kuantitas maupun kualitasnya. Namun kondisi air tanah dapat berbeda - beda di setiap daerah. Banyak hal yang dapat mempengaruhi kualitas dan kuantitas air tanah, yaitu keadaan akuifer, topografi, batuan, atau dapat pula berasal dari kegiatan masyarakat di daerah tersebut.

Permasalahan yang terdapat pada Desa Sukoreno, Kecamatan Sentolo, Kabupaten Kulon Progo adalah air sumur yang terasa payau. Air payau menurut Effendi (2003) adalah air dengan nilai TDS (Total Dissolved Solid) yaitu 1001 - 3000 mg/L. Hasil penelitian menunjukkan bahwa air tanah tersebut merupakan connate water. Menurut Bahagiarti dkk (2008), connate water 
merupakan air yang secara genetik terbentuk bersamaan dengan pembentukan sedimen yang mengandungnya.

Pengujian sampel air tanah yang diambil dari salah satu sumur gali milik warga menunjukkan bahwa nilai TDS, salinitas, natrium $(\mathrm{Na})$, sulfat $\left(\mathrm{SO}_{4}{ }^{2-}\right)$, kesadahan, bikarbonat $\left(\mathrm{HCO}_{3}{ }^{-}\right)$, dan kalium $\left(\mathrm{K}^{+}\right)$berturut - turut adalah $1520 \mathrm{mg} / \mathrm{L}, 1,6 \%$, 482,41 mg/L, $774 \mathrm{mg} / \mathrm{L}, 445,3$ $\mathrm{mg} / \mathrm{L}$,dan $11 \mathrm{mg} / \mathrm{L}$. Parameter-parameter tersebut saling berkaitan, dimana salinitas air tanah dapat disebabkan oleh air fosil (connate water) (Iwaco dan Waseco, 1994). Ion utama, yaitu natrium, klorida, kalsium, magnesium, kalium, sulfat, dan bikarbonat dalam mempengaruhi salinitas (Damayanti, 2015.

Pada penelitian ini, dilakukan proses adsoprsi untuk mengolah air payau yang ada di Desa Sukoreno, Kecamatan Sentolo, Kabupaten Kulon Progo. Adsorben yang digunakan yaitu zeolit dan bentonit sebagai media untuk pengolahan air payau. Zeolit merupakan alumosilikat dengan rumus umum (MeII, MeI2) $\mathrm{O} \cdot \mathrm{Al} 2 \mathrm{O} 3 \cdot \mathrm{nSiO} 2 \cdot \mathrm{p} \mathrm{H} 2 \mathrm{O}$. Zeolit dapat dianggap sebagai turunan silikat dimana Si sebagian tersubstitusi oleh Al. Penggunaan zeolit alam sebagai media adsorpsi dalam proses pengolahan air sudah sangat luas karena tingginya kemampuan zeolit dalam proses pertukaran kation (Wang dan Peng, 2010). Selain itu, zeolite juga banyak digunakan sebagai adsorben karena biaya yang dibutuhkan rendah serta dapat menyisihkan logam berat, ammonium, fosfor, material organik terlarut, kation serta zat radioaktif (Kotoulas dkk., 2019). Zeolit sangat tepat digunakan untuk proses pertukaran ion (misalnya pelunakan) tapi tidak untuk adsorpsi zat organik netral (Worch, 2012). Gustian dkk (2005) menyebutkan bahwa penggunaan zeolit dalam penurunan salinitas berfungsi sebagai adsorben dan sebagai penukar ion garam dalam air, maka semakin besar luas permukaan zeolit, semakin banyak ion - ion garam yang dapat dipertukarkan. Selain itu, pada penelitian ini juga digunakan bentonit sebagai adsorben. Penggunaan bentonit sebagai adsorben dalam proses pengolahan air, dilakukan karena sifat bentonit yaitu memiliki luas permukaan, berpori dan memiliki situs aktif sehingga bentonit dapat diaplikasikan dalam proses adsorpsi (Prasetiowati, dkk, 2014). Selain itu, bentonit memiliki dua lapisan interlayer yang berbeda sehingga mempunyai kemampuan tukar kation yang tinggi (Faizal dkk., 2014). Oleh karena itu, penelitian ini bertujuan untuk mengetahui tingkat efektivitas filter zeolit dan bentonit dalam pengolahan air payau.

\section{METODOLOGI PENELITIAN}

Bahan baku zeolit dan bentonit yang digunakan untuk penelitian merupakan asli, zeolit diambil langsung di Kecamatan Gedangsari, Kabupaten Gunung Kidul, dan bentonit di Kecamatan 
Nanggulan, Kabupaten Kulon Progo, Daerah Istimewa Yogyakarta. Kedua material tersebut dihancurkan sehingga diperoleh ukuran $0,3 \mathrm{~cm}$ atau 7 mesh. Aktivasi yang dilakukan adalah secara fisika, yaitu pengovenan selama 1 jam dengan suhu $110^{\circ} \mathrm{C}$. Mahaddila dkk (2013) menyatakan bahwa pengovenan bertujuan untuk menghidrasi material sehingga memiliki tingkat efektivitas adsorpsi yang tinggi.

Proses adsorbsi dilakukan dengan menggunakan 2 buah kolom yang masing - masing bervolume $10 \mathrm{~L}$ dengan metode fixed bed/ semi batch column (Gambar 1). Pengolahan dilakukan dengan HLR (Hydraulic Loading Rate) yaitu 0,25 m/jam, yang sama pada setiap kolom. Parameter yang digunakan adalah TDS, salinitas, natrium $(\mathrm{Na})$, sulfat $\left(\mathrm{SO}_{4}{ }^{2-}\right)$, kesadahan, bikarbonat $\left(\mathrm{HCO}_{3}{ }^{-}\right)$, dan kalium $\left(\mathrm{K}^{+}\right)$. Penelitian dilakukan selama 7 hari $(2 \mathrm{kali}$ running per hari dalam waktu 75 menit setiap running).
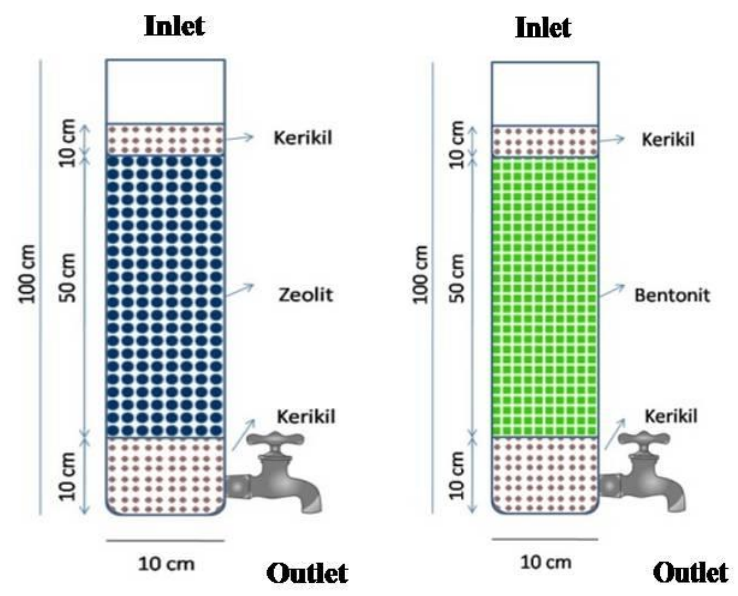

Gambar 1. Rancangan Filter Pengolahan Air Payau

\section{HASIL DAN PEMBAHASAN}

\subsection{Pengujian Masing - Masing Parameter}

Parameter yang diuji dalam penelitian ini adalah TDS, salinitas, natrium, sulfat, kesadahan, bikarbonat, dan kalium. Pengujian TDS dilakukan setiap hari menggunakan uji cepat dengan EC Meter ditunjukkan oleh Tabel 1.

Pengujian salinitas pada air yang ditunjukkan di Tabel 2 hanya dilakukan pada pengolahan pertama di hari ke 1, 3 dan 7 atau pengolahan ke 1, 5, dan 13. Pemilihan waktu - waktu tertentu ini didasarkan oleh pertimbangan saat adsorben masih segar, adsorben diperkirakan mulai jenuh, dan adsorben sudah sangat jenuh. 
Tabel 1. Hasil Pengujian Efektivitas Parameter TDS

\begin{tabular}{cccccc}
\hline \multirow{2}{*}{ Pengujian } & \multicolumn{2}{c}{ Zeolit } & \multicolumn{2}{c}{ Bentonit } \\
\cline { 3 - 6 } & & $\begin{array}{c}\text { TDS } \\
\text { Hari }\end{array}$ & $\begin{array}{c}\text { Efektivitas } \\
(\%)\end{array}$ & $\begin{array}{c}\text { TDS } \\
(\mathrm{mg} / \mathrm{L})\end{array}$ & $\begin{array}{c}\text { Efektivitas } \\
(\%)\end{array}$ \\
\hline \multicolumn{2}{c}{ Konsentrasi Awal } & \multicolumn{2}{c}{1680} & & 1680 \\
\hline \multirow{2}{*}{ H 1 } & 08.00 & 978 & $41,78 \%$ & 849 & $49,46 \%$ \\
\cline { 2 - 6 } & 12.00 & 1341 & $20,18 \%$ & 1342 & $20,11 \%$ \\
\hline \multirow{2}{*}{ H 2 } & 08.00 & 1336 & $20,48 \%$ & 1466 & $12,74 \%$ \\
\hline \multirow{2}{*}{ H 3 } & 12.00 & 1423 & $15,30 \%$ & 1565 & $6,85 \%$ \\
\hline \multirow{2}{*}{ H 4 } & 08.00 & 1403 & $16,49 \%$ & 1546 & $7,97 \%$ \\
\hline \multirow{2}{*}{ H 5 } & 12.00 & 1470 & $12,5 \%$ & 1574 & $6,31 \%$ \\
\hline \multirow{2}{*}{ H 6 } & 08.00 & 1430 & $14,88 \%$ & 1528 & $9,05 \%$ \\
\hline \multirow{2}{*}{ H 7 } & 12.00 & 1490 & $11,31 \%$ & 1595 & $5,06 \%$ \\
\hline & 12.00 & 1386 & $17,5 \%$ & 1569 & $6,61 \%$ \\
\hline
\end{tabular}

Tabel 2. Hasil Pengujian Efektivitas Parameter Salinitas

\begin{tabular}{|c|c|c|c|c|c|}
\hline \multirow{2}{*}{\multicolumn{2}{|c|}{ Pengujian }} & \multicolumn{2}{|c|}{ Zeolit } & \multicolumn{2}{|c|}{ Bentonit } \\
\hline & & \multirow{2}{*}{$\begin{array}{c}\text { Salnitas } \\
(\mathrm{U} / 00)\end{array}$} & \multirow{2}{*}{$\begin{array}{c}\text { Efektivitas } \\
(\%)\end{array}$} & \multirow{2}{*}{$\begin{array}{c}\text { Salinitas } \\
(\mathrm{U} / 00)\end{array}$} & \multirow{2}{*}{$\begin{array}{c}\text { Efektivitas } \\
(\%)\end{array}$} \\
\hline Hari & Waktu & & & & \\
\hline \multicolumn{2}{|c|}{ Konsentrasi Awal } & \multicolumn{2}{|c|}{1,5} & \multicolumn{2}{|c|}{1,5} \\
\hline H 1 & 08.00 & 0,9 & $40 \%$ & 0,8 & $46,67 \%$ \\
\hline $\mathrm{H} 3$ & 08.00 & 2,0 & $-33,3 \%$ & 1,8 & $-20 \%$ \\
\hline $\mathrm{H} 7$ & 08.00 & 1,4 & $6,67 \%$ & 1,4 & $6,67 \%$ \\
\hline
\end{tabular}

Sumber: Balai Besar Teknik Kesehatan Lingkungan dan Pengendalian Penyakit Yogyakarta , 2018

Pengujian natrium pada air yang ditunjukkan pada Tabel 3 hanya dilakukan pada pengolahan pertama di hari ke 1, 3 dan 7 atau pengolahan ke 1,5, dan 13. Pemilihan waktu - waktu tertentu ini didasarkan oleh pertimbangan saat adsorben masih segar, adsorben diperkirakan mulai jenuh, dan adsorben sudah sangat jenuh.

Pengujian sulfat pada air yang ditunjukkan pada Tabel 4 hanya dilakukan pada pengolahan pertama di hari ke 1, 3 dan 7 atau pengolahan ke 1,5, dan 13. Pemilihan waktu - waktu tertentu ini didasarkan oleh pertimbangan saat adsorben masih segar, adsorben diperkirakan mulai jenuh, dan adsorben sudah sangat jenuh. 
Tabel 3. Hasil Pengujian Efektivitas Parameter Natrium

\begin{tabular}{cccccc}
\hline \multirow{2}{*}{ Pengujian } & \multicolumn{2}{c}{ Zeolit } & \multicolumn{2}{c}{ Bentonit } \\
\cline { 3 - 6 } & Natrium & Efektivitas & Natrium & Efektivitas \\
$(\mathrm{mg} / \mathrm{L})$ & $(\%)$ & $(\mathrm{mg} / \mathrm{L})$ & $(\%)$ \\
\hline \multicolumn{2}{c}{ Hari } & Waktu & & \multicolumn{2}{c}{502} \\
\hline \multicolumn{2}{l}{ Konsentrasi Awal } & \multicolumn{2}{c}{502} & 125 & $75,10 \%$ \\
\hline H 1 & 08.00 & 138 & $72,51 \%$ & 499 & $0,60 \%$ \\
\hline H 3 & 08.00 & 320 & $36,25 \%$ & 626 & $-24,70 \%$ \\
\hline H 7 & 08.00 & 459 & $8,57 \%$ &
\end{tabular}

Sumber: Balai Besar Teknik Kesehatan Lingkungan dan Pengendalian Penyakit Yogyakarta , 2018

Tabel 4. Hasil Pengujian Efektivitas Parameter Sulfat

\begin{tabular}{cccccc}
\hline \multirow{2}{*}{ Pengujian } & \multicolumn{2}{c}{ Zeolit } & \multicolumn{2}{c}{ Bentonit } \\
\cline { 3 - 6 } & $\begin{array}{c}\text { Sulfat } \\
(\mathrm{mg} / \mathrm{L})\end{array}$ & $\begin{array}{c}\text { Efektivitas } \\
(\%)\end{array}$ & $\begin{array}{c}\text { Sulfat } \\
(\mathrm{mg} / \mathrm{L})\end{array}$ & $\begin{array}{c}\text { Efektivitas } \\
(\%)\end{array}$ \\
\hline \multicolumn{2}{c}{ Hari } & Waktu & & \multicolumn{2}{c}{1.107} \\
\hline \multicolumn{2}{l}{ Konsentrasi Awal } & \multicolumn{2}{c}{1.107} & 600 & $45,80 \%$ \\
\hline H 1 & 08.00 & 740 & $33,15 \%$ & 643 & $41,92 \%$ \\
\hline H 3 & 08.00 & 627 & $43,36 \%$ & 643 \\
\hline H 7 & 08.00 & 1.718 & $-55,19 \%$ & 1.845 & $-66,67 \%$ \\
\hline
\end{tabular}

Sumber: Balai Besar Teknik Kesehatan Lingkungan dan Pengendalian Penyakit Yogyakarta, 2018

Pengujian kesadahan pada air yang ditunjukkan pada Tabel 5 hanya dilakukan pada pengolahan pertama di hari ke 1, 3 dan 7 atau pengolahan ke 1,5, dan 13. Pemilihan waktu - waktu tertentu ini didasarkan oleh pertimbangan saat adsorben masih segar, adsorben diperkirakan mulai jenuh, dan adsorben sudah sangat jenuh.

Tabel 5. Hasil Pengujian Efektivitas Parameter Kesadahan

\begin{tabular}{|c|c|c|c|c|c|}
\hline \multirow{2}{*}{\multicolumn{2}{|c|}{ Pengujian }} & \multicolumn{2}{|c|}{ Zeolit } & \multicolumn{2}{|c|}{ Bentonit } \\
\hline & & \multirow{2}{*}{$\begin{array}{c}\text { Kesadahan } \\
(\mathrm{mg} / \mathrm{L})\end{array}$} & \multirow{2}{*}{$\begin{array}{c}\text { Efektivitas } \\
(\%)\end{array}$} & \multirow{2}{*}{$\begin{array}{c}\text { Kesadahan } \\
(\mathrm{mg} / \mathrm{L})\end{array}$} & \multirow{2}{*}{$\begin{array}{c}\text { Efektivitas } \\
(\%)\end{array}$} \\
\hline Hari & Waktu & & & & \\
\hline \multicolumn{2}{|c|}{ Konsentrasi Awal } & \multicolumn{2}{|c|}{536} & \multicolumn{2}{|c|}{536} \\
\hline H 1 & 08.00 & 832 & $-55,22 \%$ & 656 & $-22,39 \%$ \\
\hline $\mathrm{H} 3$ & 08.00 & $1.115,58$ & $-108,13 \%$ & 582,91 & $-8,75 \%$ \\
\hline H 7 & 08.00 & 733,67 & $-36,88 \%$ & 311,56 & $41,87 \%$ \\
\hline
\end{tabular}

Sumber: Balai Besar Teknik Kesehatan Lingkungan dan Pengendalian Penyakit Yogyakarta , 2018

Pengujian $\mathrm{HCO}_{3}$ pada air ditunjukkan pada Tabel 6 dan hanya dilakukan pada pengolahan pertama di hari ke 1, 3 dan 7 atau pengolahan ke 1, 5, dan 13. Pemilihan waktu - waktu tertentu 
ini didasarkan oleh pertimbangan saat adsorben masih segar, adsorben diperkirakan mulai jenuh, dan adsorben sudah sangat jenuh.

Tabel 6. Hasil Pengujian Efektivitas Parameter Bikarbonat

\begin{tabular}{|c|c|c|c|c|c|}
\hline \multirow{2}{*}{\multicolumn{2}{|c|}{ Pengujian }} & \multicolumn{2}{|c|}{ Zeolit } & \multicolumn{2}{|c|}{ Bentonit } \\
\hline & & \multirow{2}{*}{$\begin{array}{l}\mathrm{HCO}_{3} \\
(\mathrm{mg} / \mathrm{L})\end{array}$} & \multirow{2}{*}{$\begin{array}{c}\text { Efektivitas } \\
(\%)\end{array}$} & \multirow{2}{*}{$\begin{array}{c}\mathrm{HCO}_{3} \\
(\mathrm{mg} / \mathrm{L})\end{array}$} & \multirow{2}{*}{$\begin{array}{c}\text { Efektivitas } \\
(\%)\end{array}$} \\
\hline Hari & Waktu & & & & \\
\hline \multicolumn{2}{|c|}{ Konsentrasi Awal } & \multicolumn{2}{|c|}{658,8} & \multicolumn{2}{|c|}{658,8} \\
\hline H 1 & 08.00 & 308,7 & $53,14 \%$ & 408,7 & $37,96 \%$ \\
\hline $\mathrm{H} 3$ & 08.00 & 451,4 & $31,48 \%$ & 463,6 & $29,63 \%$ \\
\hline H 7 & 08.00 & 610 & $7,41 \%$ & 515,45 & $21,76 \%$ \\
\hline
\end{tabular}

Sumber: Balai Besar Teknik Kesehatan Lingkungan dan Pengendalian Penyakit Yogyakarta , 2018

Pengujian kalium pada air yang ditunjukkan pada Tabel 7 hanya dilakukan pada pengolahan pertama di hari ke 1, 3 dan 7 atau pengolahan ke 1, 5, dan 13. Pemilihan waktu - waktu tertentu ini didasarkan oleh pertimbangan saat adsorben masih segar, adsorben diperkirakan mulai jenuh, dan adsorben sudah sangat jenuh.

Tabel 7. Hasil Pengujian Efektivitas Parameter Kalium

\begin{tabular}{|c|c|c|c|c|c|}
\hline \multirow{2}{*}{\multicolumn{2}{|c|}{ Pengujian }} & \multicolumn{2}{|c|}{ Zeolit } & \multicolumn{2}{|c|}{ Bentonit } \\
\hline & & \multirow{2}{*}{$\begin{array}{l}\text { Kalium } \\
(\mathrm{mg} / \mathrm{L})\end{array}$} & \multirow{2}{*}{$\begin{array}{c}\text { Efektivitas } \\
(\%)\end{array}$} & \multirow{2}{*}{$\begin{array}{c}\text { Kalium } \\
(\mathrm{mg} / \mathrm{L})\end{array}$} & \multirow{2}{*}{$\begin{array}{c}\text { Efektivitas } \\
(\%)\end{array}$} \\
\hline Hari & Waktu & & & & \\
\hline \multicolumn{2}{|c|}{ Konsentrasi Awal } & \multicolumn{2}{|c|}{9} & \multicolumn{2}{|c|}{9} \\
\hline H 1 & 08.00 & 7 & $22,22 \%$ & 12 & $-33,33 \%$ \\
\hline $\mathrm{H} 3$ & 08.00 & 1 & $88,89 \%$ & 10 & $-11,11 \%$ \\
\hline H 7 & 08.00 & 18 & $-100 \%$ & 17 & $-88,89 \%$ \\
\hline
\end{tabular}

Sumber: Balai Besar Teknik Kesehatan Lingkungan dan Pengendalian Penyakit Yogyakarta , 2018

\subsection{Hubungan Antar Parameter}

Masing - masing material adsorben memiliki daya adsorpsi dan kapasitas tukar kation. Daya adsorpsi disebabkan karena adanya struktur adsorben yang membentuk rongga - rongga. Sedangkan kapasitas tukar kation, disebabkan karena kandungan kation dalam adsorben tersebut (Mahaddila dkk, 2013 dan Prasetiowati dkk, 2014). Namun seperti terlihat pada Gambar 2, 3, dan 4, tidak semua parameter memiliki pola perubahan efektivitas yang sama, terdapat parameter yang memiliki anomali sehingga tampak berbeda dengan parameter lainnya.

Grafik yang ditunjukkan oleh Gambar 2 merupakan parameter TDS pada masing - masing adsorben. Tampak bahwa ektivitas pengolahan dengan kedua material tersebut memiliki pola yang semakin menurun. Namun terlihat perbedaannya yaitu tingkat efektivitas penurunan TDS 
zeolit masih lebih tinggi dibandingkan dengan efektivitas bentonit. Selain itu, zeolit terlihat memilki fluktuasi, sedangkan bentonit cederung lebih datar. Hal tersebut menunjukkan bahwa bentonit lebih cepat jenuh dibanding dengan zeolit, karena bentonit memiliki sifat kembang kerut yang tinggi seperti mineral lempung lainnya. Grafik tiga dan keempat membandingkan antara parameter salinitas, natrium, sulfat, $\mathrm{HCO}_{3}$, kalium dan kesadahan pada masing - masing adsorben.

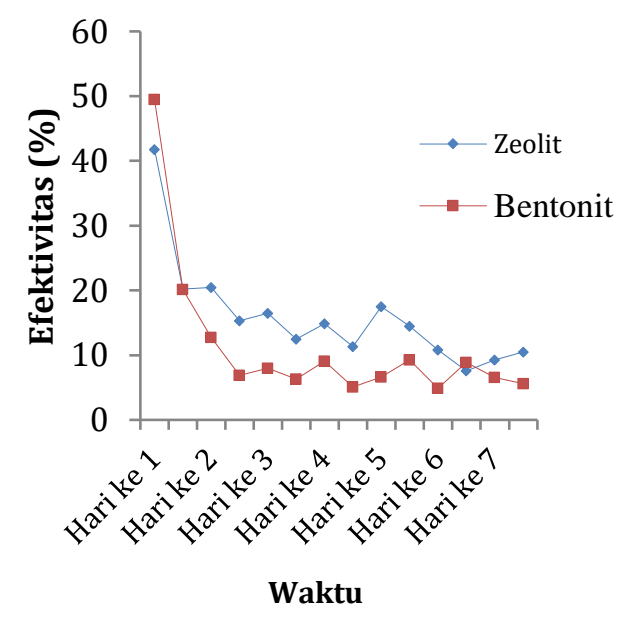

Gambar 2. Efektivitas Penurunan TDS dengan Zeolit dan Bentonit

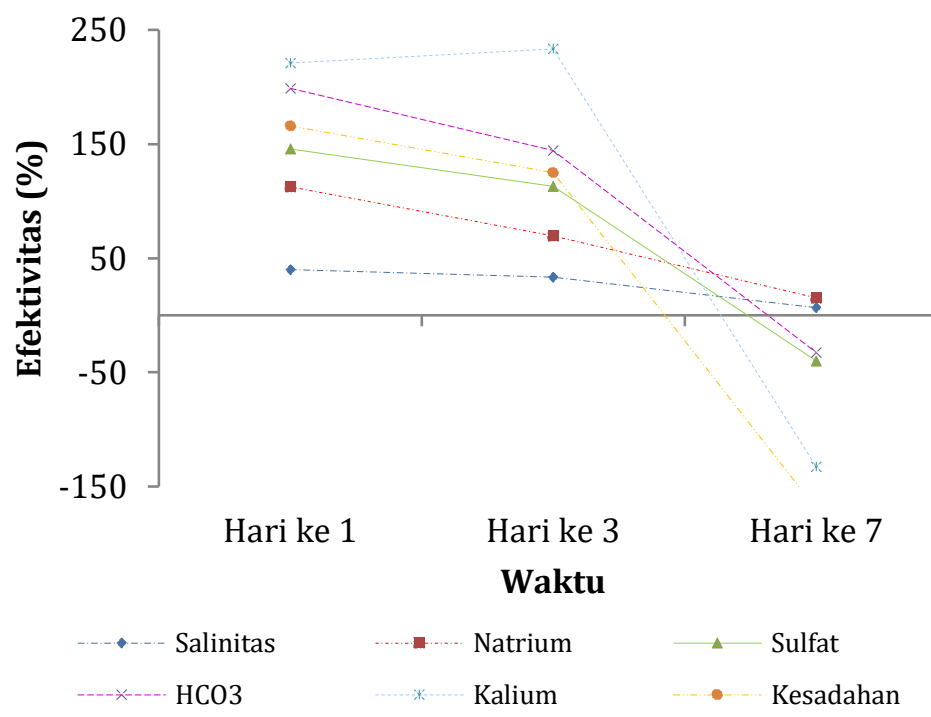

Gambar 3. Efektivitas Penurunan Parameter Kimia dengan Zeolit 


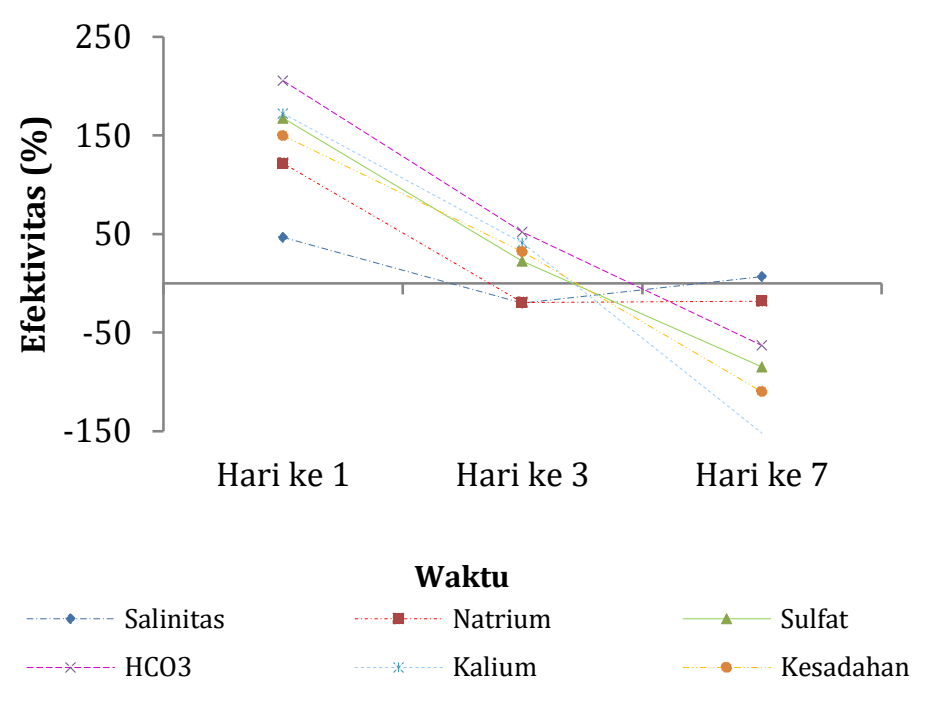

Gambar 4. Efektivitas Penurunan Parameter Kimia dengan Bentonit

Efektivitas setiap parameter menunjukkan pola yang cenderung sama, yaitu menurun meskipun penurunan masing - masing parameter berbeda. Parameter natrium, sulfat, kesadahan, dan kalium mencapai tingkat efektivitas minus pada hari ketujuh yang berarti konsentrasi parameter - parameter tersebut dalam air mengalami peningkatan hingga melebihi konsentrasi awal. Sedangkan pada Gambar 4, grafik juga menunjukkan pola yang mirip, yaitu mengalami penurunan hingga hari ketujuh, hanya saja terdapat perbedaan pada parameter salinitas, yang cenderung stabil mulai hari ketiga pengolahan. Parameter - parameter yang lainnya mengalami penurunan efektivitas hiingga mencapai minus, yang berarti konsentrasi hingga hari ketujuh mengalami peningkatan melebihi konsentrasi awal.

Penelitian yang telah dilakukan oleh Atikah (2017) menunjukkan bahwa zeolit yang telah diaktivasi secara fisika dan kimia terbukti mampu melakukan adsropsi dan pertukaran kation. Kemampuan tukar kation yang dimiliki zeolit turut didukung dengan adanya kandungan aluminium silikat. Efektivitas yang tidak maksimal karena terdapat kandungan - kandungan oksida bebas di permukaan adsorben seperti $\mathrm{Al}_{2} \mathrm{O}_{3}, \mathrm{SiO}_{2}, \mathrm{CaO}, \mathrm{MgO}, \mathrm{Na}_{2} \mathrm{O}, \mathrm{K}_{2} \mathrm{O}$ dapat menutupi pori - pori atau situs aktif sehingga dapat menurunkan kapasitas adsorpsi maupun sifat katalis (Mahaddila dkk , 2013). Kandungan ini seharusnya dapat terlebih dahulu dihilangkan dengan aktivasi kimiawi. Aktivasi secara kimiawi dilakukan dengan asam atau basa dengan tujuan membersihkan permukaan pori, membuang senyawa pengotor, dan mengatur kembali letak atom yang dapat dipergunakan. Pengaktifan dengan asam mineral akan melarutkan logam alkali seperti $\mathrm{Ca}^{2+}, \mathrm{K}^{+}, \mathrm{Na}^{+}$, dan $\mathrm{Mg}^{2+}$ yang menutup sebagian rongga pori 
dan pengaktifan dengan $\mathrm{H}^{+}$dalam ruang interlamier sehingga lebih porous dan permukaan lebih aktif (Atikah, 2017)

\section{Kesimpulan}

Pemanfaatan zeolit dan bentonit sebagai adsorben dalam pengolahan air payau kurang maksimal, karena tingkat efektivitas yang diberikan kedua adsorben tidak stabil. Namun secara keseluruhan, kemampuan adsorpsi zeolit lebih tinggi dibandingkan dengan bentonit. Hal ini disebabkan oleh aktivasi yang tidak optimal, sehingga fungsi kedua material tersebut tidak berjalan dengan baik. Berdasarkan penelitian lain yang telah dilakukan, aktivasi secara kimia dengan asam kuat perlu dicoba untuk dilakukan, karena lebih efektif dibandingkan dengan aktivasi fisik.

\section{DAFTAR PUSTAKA}

Assegaf, Abdurrachman, dkk. (2017). Salinitas Airtanah Akifer Tertekan Kedalaman 10 - 20m Daerah Kalideres, Cengkareng, Jakarta Barat. Ris. Geo. Tam, 27 (1):15-25

Atikah, Wulan Safrihatini. (2017). Potensi Zeolit Alam Gunung Kidul Teraktivasi Sebagai Media Adsorben Pewarna Tekstil. Politeknik STTT Bandung

Bahagiarti, Sari dan Bambang Sutedjo. (2008). Proses - Proses Hidrogeologi. UPN Veteran Yogyakarta, Yogyakarta.

Damayanti, Annisa Dwi. (2015). Studi Salinitas Air Tanah Dangkal di Daerah Pesisir Bagian Utara Kota Makassar. Program Studi Teknik Lingkungan, Jurusan Teknik Sipil, Fakultas Teknik, Universitas Hasanudin.

Effendi, Hefni. (2003). Telaah Kualitas Air. Sleman: Kanisius

Faizal, M., Hariyani dan Fitri, Rindy Mutia. (2014). Pengolahan Air Limbah yang Mengandung Logam Cd Menggunakan Komposit Adsorbent dengan Bentonit dan $\mathrm{Fe}_{3} \mathrm{O}_{4}$. Jurnal Teknik Kimia, 20 (3): 66-72.

Gustian, Irfan dan Totok E. Suharto. (2005). Studi Penurunan Salinitas Air dengan Menggunakan Zeolit Alam yang Berasal dari Bengkulu. Jurnal Gradien, 1(1) : 38 - 42

Iwaco dan Waseco. DHV Consultants, Delft Hydraulics, TNO, Persero PT. Indah Karya, PT.Kwarsa Hexagon, and PT. Wiratman \& Associates. (1994). Jabotabek Water Resources Management Study, Final Report, Ministry of Public Works, Directorate 
General of Water Resources Development, Jakarta.

Katoulas, A., Agathou, D., Triantaphyllidou, IE., Tatolius, T., Ajratos, CS., Takerlekopolou, AG dan Vayenas, DV. (2019). Zeolite as a Potential Medium for Ammonium Recovery and Second Cheese Whey Treatment. Water, 11(1): 136

Mahaddila, Febri Putra dan Putra, Ardian. (2013). Pemanfaatan Batu Apung Sebagai Sumber Silika dalam Pembuatan Zeolit Sintesis. Jurnal Fisika Unsoed, 2(4): 262-268

Prasetiowati, Yuni dan Toeti Koestiari. (2014). Kapasitas Bentonit Teknis sebagai Adsorben Ion $\mathrm{Cd}^{2+}$. Journal of Chemistry, 3 (3): 194-200

Wang, Shaobin dan Peng, Yuelian. (2010). Natural zeolites as effective adsorbents in water and wastewater treatment. Chemical Engineering Journal, 156(1): 11-24

Worch, Eckhard.(2012). Adsorption Technology in Water Treatment. Germany: Dresden University of Technology 